\title{
Re-engineering: leanness issues in automatic assembly
}

\author{
R.M. Molfino, A. Lacchini, G. Maggiolo, \\ R.C. Michelini and R.P. Razzoli \\ DIMEC: Industrial Robot Design Research Group \\ University of Genova \\ Via All'Opera Pia 15A, 16145 Genova, Italy \\ Tel +3910353 2857, Fax +39103532974 \\ e-mail:pmar@dimec.unige.it
}

\begin{abstract}
Household appliances assembly is critical process, with steps having resort to manual operations, to achieve cheap final products with customer satisfaction and to win world-wide competitiveness. The paper investigates the joint product-andprocess design (by simultaneous engineering rules) and assesses the return figures (by expert simulation) obtained exploiting modular robotic facilities.
\end{abstract}

Keywords

Household appliances integration, modular robot assembly

\section{INTRODUCTION}

The offer of household appliances is facing pressing conditions of conflict between 'equivalent' manufacturers, competing into saturated trade levels; the situation is quite close to the model of world-wide enterprises, struggling for improved market share with return on investment, by means of diversifying the production to comply with a broader mix of (potential) buyers needs. The competition issues depends on the benefits thrown on the society, properly balanced between suppliers and consumers, while complying with the environmental preservation laws and observing the rules of sustainable development. 
The domain of the household appliances is characterised by its pervasive spread and ceaseless replacing. The close connection with the domestic milieu during its operation running requires extended friendliness, with proper safety standards and environment protection precepts. The impact of current discarding makes necessary the regulation of scraps removal and the fostering of reuse options. These many factors turn into costs, that shall be directly supported the companies and the individuals which actually benefit from the items, with minimal impact on the environment and on the resources wiping out.

The subject is quite important since the product development and manufacturing shall dynamically incorporate the supplier constraints and the user satisfaction with the authority prescriptions, while producing cheapest artefacts as compared with competing enterprises. The success depends on the continuous monitoring the value added along the material flow, so that every function or resource change is carefully poised against the return effectively enabled. In such a context, even the innovation brought forth by information technology is subject to scrupulous metering, with due attention on the leanness fall-out (Acaccia et al., 1986, 1987, 1988, 1991, 1993, 1993, Michelini et al., 1990, 1994, Zaremba and Prasad, 1994).

Each offered product, in fact, finally presents as the output of a ripe technology, with little modifications, mainly supported by the options of mechatronics or, sometimes, fixed by regulation bills. The enterprises' competitivity is sought by joining internally ruled achievements, such as: to increase productivity, to compress time to market, to improve quality standards, etc.; and externally enforced requests, such as: to reduce environmental impact of refluents, to improve performance and energy saving, to adapt the fitting out for better or safer operation, etc. (Tzafestas, 1997). A washing machine, for instance, has to cut down the acoustic emission and have a variety of programmes properly expanded to cover all different requirements for garments or other domestic items that, in the practice, house keepers are interested to wash.

The effectiveness, in such a context, is a quite subtle re-engineering business to reach customer satisfaction with extra outfits, possibly, obtained by specialised suppliers, while preserving the artefact low-price, by means of: - reducing complexity; · using design-for-assembly schemes; - exploiting modularity of the product and of the process; or, as a all: $\cdot$ enabling scope-oriented contrivances and, at the same time, removing any steps which is not proved to add value to the offer.

\section{A SAMPLE CASE DEVELOPMENT}

The case histories in re-engineering present with diversified conditional elements and the planning out for efficiency shall, accordingly, adapt to the peculiarities of each contexts. Still, the permanent requirements of 'leanness' (Womack et al., 1990) and of 'economy of scope' (Michelini et al., 1999) share common rules, such as: 
- at the organisational level:

- to balance the overall business management process: the integration needs cover suppliers and dealers to avoid unnecessary function duplication;

- to promote team activity for solving current problems by a multi-disciplinary approach with multi-skilled experts;

- to build-up co-operative relations for stacking insights as team culture and making not desirable the application for new company;

- at the co-ordination level:

- to concentrate staff and support functions into the primary production process, verifying their ability of 'adding' value to the artefacts;

- to enable prompt visibility of incorrect trends, with decentralised responsibility for the selection of the restoring actions;

- to exploit the enterprise information system for supporting the transparency of quality data and of cost affectation;

- at the executional level:

- to remove over-protection and over-production, avoiding not necessary functions, set-apart resources, stock pile-up, etc.;

- to enable just-in-time logistics, balancing the distributed capacities and exploiting on-line the facilities flexibility;

- to develop proactive monitoring maintenance, for zero-defect manufacturing with constant preservation of specifications.

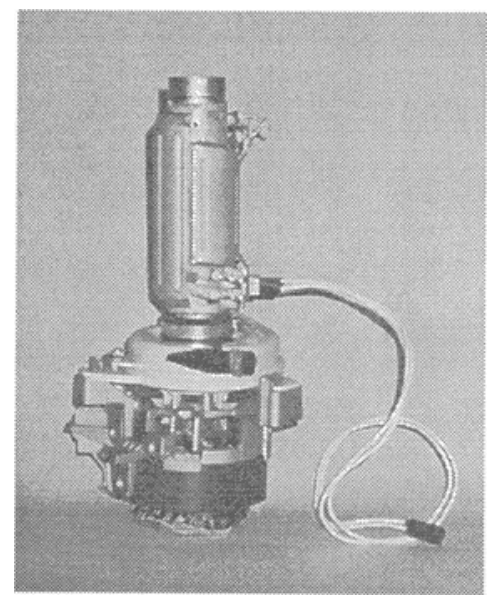

Figure 1 - View of motor+pump+heat exchanger

These, quite general, concepts are conveniently explained by means of examples. The paper deals with a development specifically related to shopfloor problems, aiming at effectiveness of the executional level tasks, namely, the efficient assembly of diversified functional groups to be used for the different models of dishwashers, simultaneously manufactured according to the market requests. The 
example case is concerned by the water heating assembly, Figure 1, composed by an electro-pump and an heat exchanger joined each other and fastened to the machine body.

The individual parts are, themselves, instrumented subassemblies, supplied by (competing) purveyors of the motor and impeller blocks, of the heating ducts, of the connection cables, of the auxiliary items (clamps, shields, etc.). Most of times, their procurement should be established as joint development, co-operatively assessed for achieving the quality data, expected for the final delivery with minimal cost-to-price ratio. The different pieces need be provided with standard features, aiming, typically, at: design-for-assembly, design-for-maintenance, design-for-recycling, etc., so to improve the artefacts in terms of manufacturing effectiveness and of life-long attributes.

According to the just shortly reviewed technical issues, the subset of product reengineering problems discussed by the paper organises as follows:

- the properties of the example functional group are reconsidered to expand automatic assembly, by low cost flexible facilities;

- the assembly resources are analysed and a functional set-up is checked, by simulation, to assess the actual achievements;

as constant rule, all issues are reported back on the basic commitment of leanness.

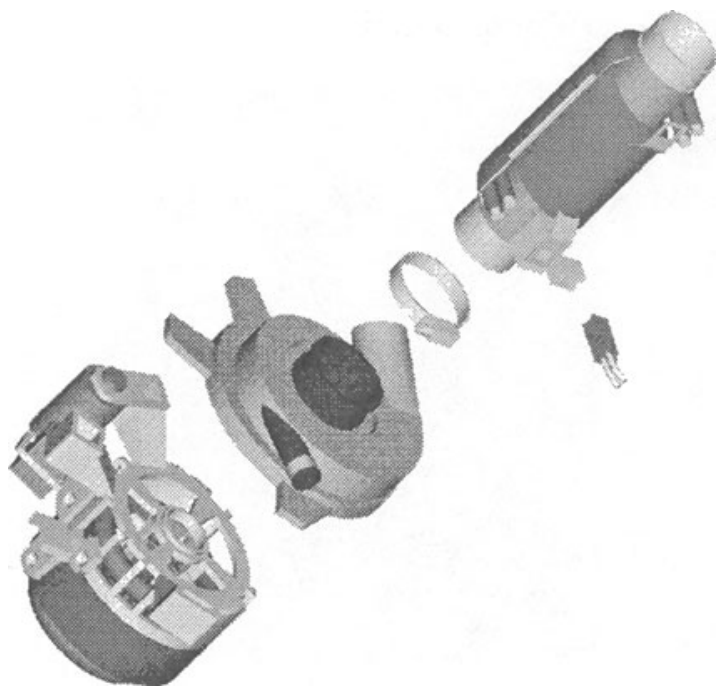

Figure 2 - Exploded view of the CAD 3D model

\section{DESIGN PHASES IMPROVEMENTS}

Household appliances manufacturing, still, largely exploits manual assembly, at least, for subsets of operations facing wide scattering of the work-cycles with 
additional requirements on the selection of the auxiliary outfittings and on the check of the outcoming products. This, in particular, is the case for the heating assemblies of the dish-washers distributed over an extended mix of models. To turn to automatic assembly, changes are required in order: - to equip the pieces with properly shaped fittings, for simplifying recognition, handling and orientation; - to equip the assembly stand with proper fixtures and rigs, for supporting the work cycles accomplishment and dismissal certification.

The first objective is simplified by performing the redesign sequences with the help of a parametric CAD, such as Pro/Engineer. First, the 3D models of the different components are generated, then a series of different re-shaping alternatives is studied. For the motor and impeller block, for instance the redesign might involved, Fig 2: the protrusions with the threaded holes for the interconnection to the dish washer body; the swept blend geometry of the pump helical diffuser; the coupling flanges for holding the electrical capacitor; the seat for the connecting terminals of the electrical supply; the pipe stub for the branching to the heat exchanger body; the (eventually added) eyebolts or ribs to grasp and hold the piece.

For the heat exchanger, Figure 3, moreover, the customisation might concern: the (cylindrical) external sleeve with the protrusions for the interconnection with the (helical) heating elements; the flanged support of the electrical connecting terminals; the indented pipe stub for granting the correct positioning of the part by respect to the pumping block.

Finally, locking of the two pieces is obtained by means of a hose clamp, Figure 4 , fastened by an adjustable clip, more conveniently than tightened by screw driving.
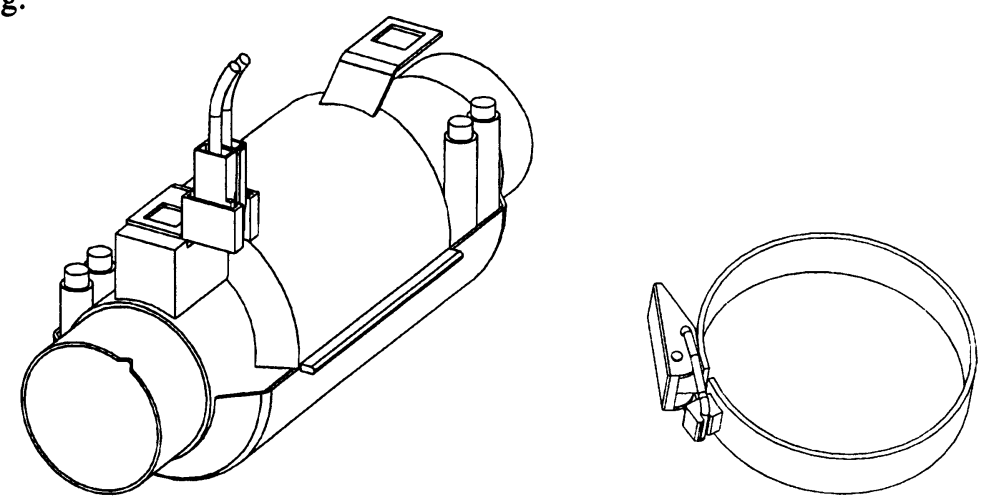

Figure 3 - The heat exchanger

Figure 4 - The adjustable hose clamp

As for the second objective, assembly oriented redesign has to comply simple rules, such as: - addition of features is a cost, then protrusions, seats, ribs, notches, etc., have to be limited; - simple shapes are the best, on condition that handling and assembling duties are supplied; - changes should be checked about their 
consistency with the nearby elements; - (sometimes) 'useless' features might be preserved, when the same piece is, also, used for extra purposes requiring them; modifications have always to be studied with the agreement of the supplier; - etc.. All in all, the over-specification of itemised details, even if it simplifies manufacturing and customisation, would result in not rewarding charges and better effectiveness might be achieved by including special fixtures (pallets, grippers, etc.) to support the specialised requirements during the manufacturing (assembly, etc.) and the full life-cycle (maintenance, etc.) of the artefact. In this case, in fact, the study demonstrates the usefulness of adaptive pallets for the feeding of the motor and impeller blocks, having series of slots to provide housing for the protrusions with the threaded holes assuring the dishwasher body connection; the resort to special fixtures, properly assorted with each actually produced household appliance model, is consistent with the considered mass production case.

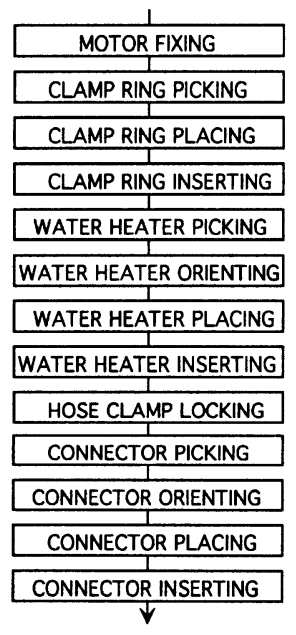

Figure 5 - Basic steps of the assembly cycle

\section{ASSEMBLY PROCESS IMPROVEMENTS}

The analysis of the assembly schedule is a critical step, to be performed since the earlier phases of the artefact specification; in view of the automatic assembling, the cycle should be decomposed into elemental job, each one leading to (intermediate) sub-assemblies, such as the heating group, typified by the present case study; then the integrator is simply concerned by combining the modules, matching the individual dishwasher model. In view of automatic assembly, the segmentation of the productive schedule, (Acaccia et al., 1990, 1990, 1996, 1996, Michelini et al., 1999), should aim at:

- single-fold jobs, as joining operations are fulfilled by the same fixturing;

- single-line schedule, as no branching to intermediate subassemblies is needed; 
then, robotics supplies the proper versatility (by refixturing, when different models are processes) and dexterity (by having resort to specialised feeding pallets and grippers).

The assembly cycle, Figure 5, is, thereafter, accomplished by a sequence plan; the robot, once recognised the artefact model depending on the electro-pump pallet, fetches the matching heat exchanger and accomplishes the joining operations.

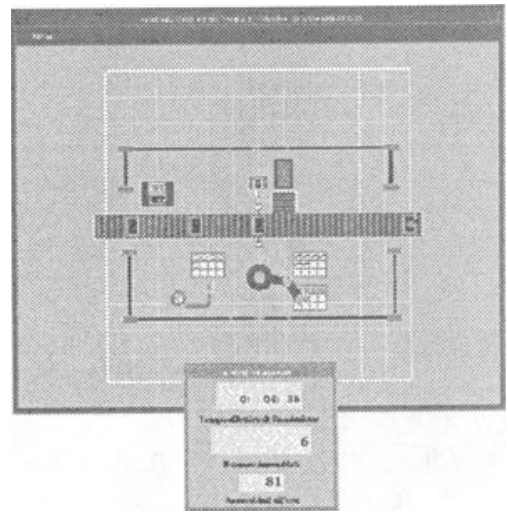

Figure 6 - The layout of the assembly cell

The pallet grants the proper attitude of the (modified) pump body; the sensorised gripper supplies the information on the correct positioning of the heater and, then, completes the clamp fastening. The lay-out of the assembly cell, Figure 6, is readily defined, in view of the described duty, around the handling robot, with the addition of the loading and the unloading stations, the clamp dispenser and the heat exchanger belt conveyor. The robot picks and places first the clamp, then the heater; finally, the spring lock is closed and the component is removed when at the unloading station.

Once the basic physical resources are chosen, the effectiveness of the assembly process is studied, by means of computer simulation. The package RAS-SIFIP is established with the aid of the MODSIM II code, which is an high level objectoriented language, with several options to simplify the current programming. Both, material and logic resources are coded into objects, with 'fields' (declarative knowledge) and 'methods' (procedural knowledge). Inheritance is used for the instanciation or modification purposes; the opportunity is particularly useful for the objects defined for coding the control actions, in order to properly supply the interlacing of execution, co-ordination and organisation ranges; of these: - the first deals with the sequencing of: palletised piece loading/unloading, clamp dispensing, heater feeding, etc.; - the tactical controller principally oversees the co-ordination of the robot motion; - the strategic controller acknowledges process progression, managing routine discontinuities and unexpected occurrences. The package RASSIFIP is, further, provided with friendly restitution to help with the preparation of 
the lay-out and with the experimentation on the set-up performance by displaying the current resources' state (Figure 7) and by providing the basic statistical indices (Figure 8) concerning operativity and productivity.

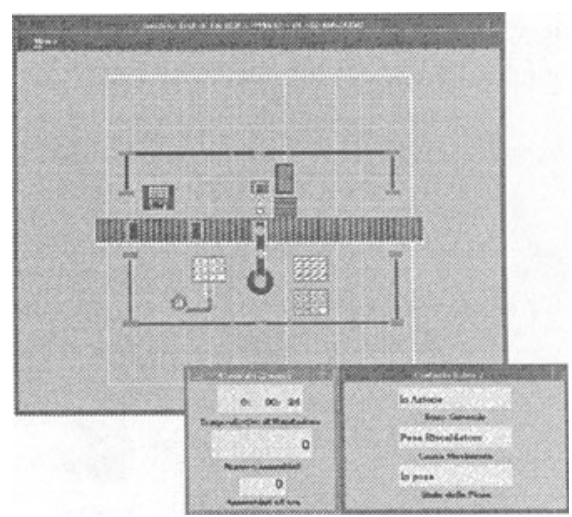

Figure 7 - Typical outputs showing the resources state

At a first glance, the manufacturing segment with the just considered assembly cycle seems quite simple and it might appear awkward to leave it for manual task, instead of looking for robots with the proper capabilities. The functional study and simulation analysis give hints about the existing difficulties and suggestions of how getting rid of them. The issues of the investigation are shortly discussed by looking at parts handling, positioning and joining problems.

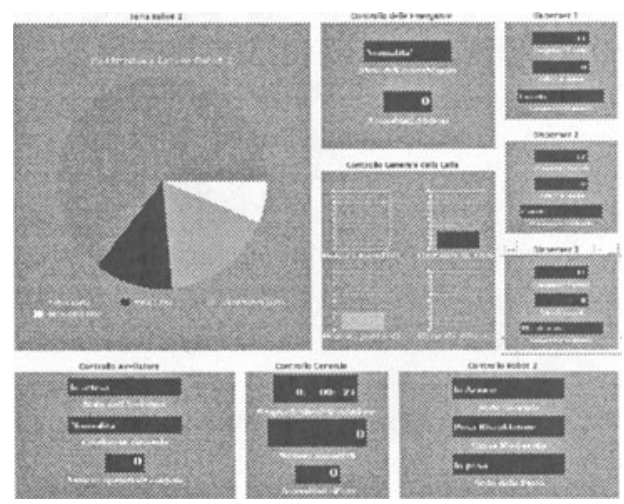

Figure 8 - Output charts giving the productivity indices

Motor-impeller block. This component prevails as size and bears a complex geometry, making robot handling uneasy: resort to a pallet simplifies positioning 
and fastening. This suggests to redesign the piece in order to standardise a set of features, shared by all the families of the similar blocks, so that the same series of adaptable pallets could be used for the different types of dishwashers. In view of that, the pallets, Figure 9, have, finally, been provided with three rigid supports (corresponding to the location for connecting the assembled group with the dishwasher body) and the blocks have, accordingly, been modified to possess corresponding planes to make easy the position trimming on these supports.
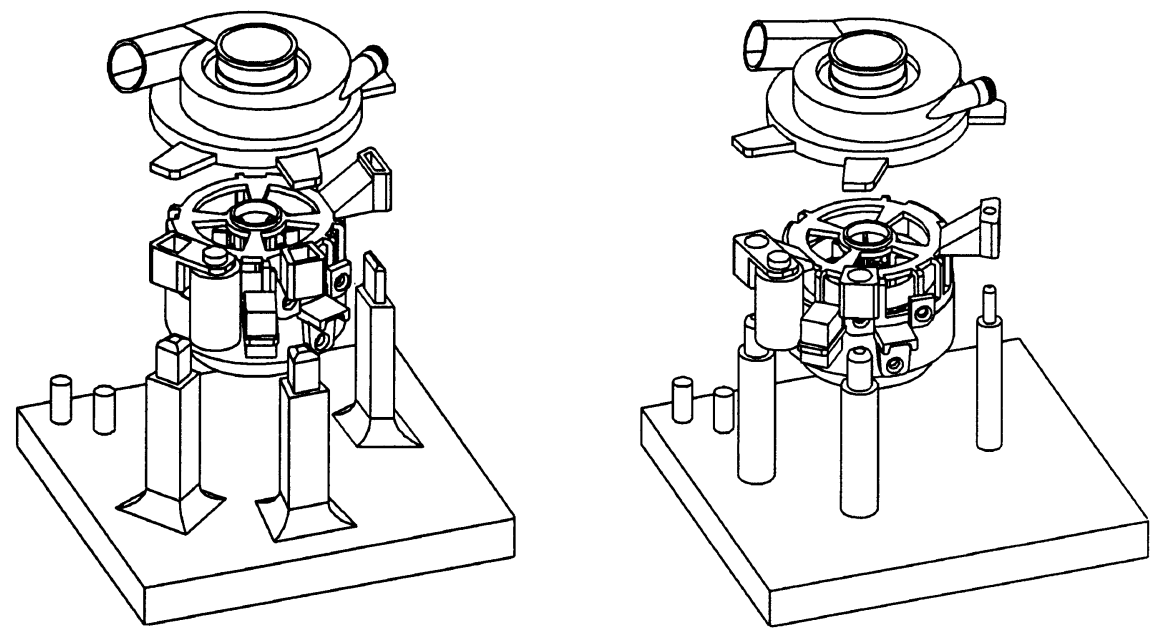

Figure 9 - Initial (left) and redesigned (right) motor-block \& supports

Hose clamp. The junction between pump and heater is obtained by tightening an adjustable clip around the mating pipe. The manual assembly usually is performed by screwing down; this, in principle, can be given is charge to a special unit, once the pieces are properly located. Alternatively the fastening can be obtained by means of an elastic clamp, with an 'open' and a 'tight' position; the latter alternative can readily be given in charge to a robot.

Heat exchanger. This component is fed up-right and the robot, once the clamp located, picks it up and place the mating pipe on the correct seat. The robot gripper can be provided with a short pole, for shutting the clamp, before leaving the hold.

Electrical connector. The vibration dispenser singularises the components (as for the elastic clamps); then the robot fetches a piece and accomplishes the correct insertion, by means of a trajectory planning which avoids the interweaving of the cable (the sample paths are properly assessed with simulation, on condition to refer to properly stated animation modules).

The analysis simply summarises few basic properties. Without entering into too many details, the choice of a SCARA robot, Figure 10, is found to be appropriate, as a standard four-mobilities architecture. It provides quite a stiff arm, for the set of standard duties; the addition of the fifth axis and of the multiple-functions end 
effector preserves the basic manipulation precision, widening dexterity, whenever useful. As for the robotic assembly cell logistic, the pallet transfer line can be obtained, combining standard modules; finally, commonly available dispensers might be included for the feeding, respectively, of clamps and connectors. The overall assembly facility results to be built by quite common (and reliable) devices.

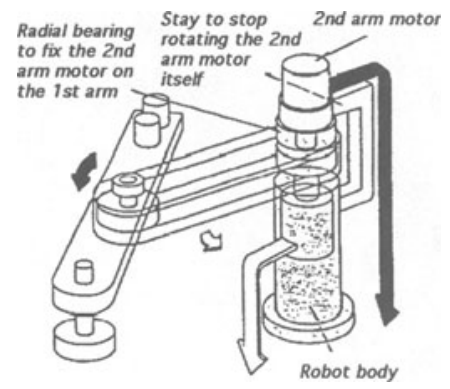

Figure 10 - A sketch of a SCARA robot

\section{COMMENTS AND CONCLUSIONS}

The return on investment from automation depends on many little changes, none conclusive alone, but supporting critical effects whether properly integrated. The evidence of the effectiveness is actually only achieved by experimenting on real running conditions. This hinders innovation, due to the cost of operating with prototypes that, certainly, have to be modified and integrated several time before reaching 'optimal' set-ups.

In such a framework, virtual reality simulation looks to be a powerful aid, on condition to pre-set a functional model of the actual behaviour of the different material and logical resources, at an appropriate level of sophistication. This means to have resort to 3D parametric CAD description (such as the one offered by ProEngineering) and to object-oriented simulation languages (such as MODSIM II). The step by step improvements and modifications can be studied and compared by low cost implementations, so that the finally selected lay-out can be assessed about its effectiveness up to the desired reliability.

The paper deals with this kind of problems and discusses the specific reengineering aspects connected with the flexible assembly of a subset of parts. Flexibility immediately addresses to robotics, but agility compels the functional leanness and productivity requires flow-shop organisation. To day, manual assembly still covers many situations; the return on investment depends on the capability of enabling additional benefits, as, for instance, the automatic management of approval tests, by generalised overseeing information modules and the assurance of the steady quality, by standardised robot assembling. 
The example case is developed, considering a particular modular assembly setup, properly implemented after the re-design of the parts, according the simultaneous engineering rules. The fixtures effectiveness, for different manufacturing strategies, is investigated by means of virtual reality simulation obtaining the comparative ranking of the actual productivity ranges. The results show how the economy of scope issues affect situations in mass-production, when life-cycle manufacturing is properly dealt with, joining, by means of the unifying transparency of the intelligent automation, the consumers' satisfaction and the sustainable development regulation.

\section{REFERENCES}

Acaccia, G.M., Michelini, R.C., Molfino, R.M., Piaggio, P.A. (1986) X-SIFIP: a knowledge-based special-purpose simulator for the development of flexible manufacturing cells, IEEE Intl. Conf. Robotics \& Automation, San Francisco, Apr., 7-10, 645-653.

Acaccia, G.M., Michelini, R.C., Molfino, R.M. (1987) Development of CADcodes for the job-integration of industrial robots, Intl. J. Robotics, 3, 371-388.

Acaccia, G.M., Michelini, R.C., Molfino, R.M., Piaggio, P.A. (1988) Data-based information structures for flexible manufacturing simulators, A. Kusiak, Ed.: Advances in Production Management Systems, Elsevier, Amsterdam, 649662.

Acaccia, G.M., DelCarretto, P., Michelini, R.C., Molfino, R.M., Rossi, G.B., Recine, M.A. (1990) Control-tuning of robotic assembly cell, IASTED Intl. Conf. CONTROL '90, Lugano, June 18-21, 75-79.

Acaccia, G.M., Massari, G., Michelini, R.C., Molfino, R.M., Rossi, G.B., Recine, M.A. (1990) Functional calibration of robotic assembly cell, Intl. Symp. Applied Modelling and Simulation, Lugano, June 18-21, 70-74.

Acaccia, G.M., Michelini, R.C., Molfino, R.M., Recine, M.A. (1991) Information reference set-up for the development of industrial multirobot systems, Intl. J. Computer Applications in Technology, vol. 4, $\mathrm{n}^{\circ} 3,137-148$.

Acaccia, G.M., Michelini, R.C., Molfino, R.M., Piaggio, M. (1993) The governfor-flexibility of manufacturing facilities: an explanatory example, Intl. $J$. Computer-Integrated Manufacturing Systems, 3, vol. 6, 149-160.

Acaccia, G.M., Callegari, M., Michelini, R.C., Molfino, R.M., Peri, P., Ricci, A. (1993) Control automation of a multioperational section for the flexible manufacturing of highly-diversified products, IFIP Intl. Conf. KNOWHSEM '93, Budapest, Apr. 20-22, 187-195.

Acaccia, G.M., Callegari, M., Michelini, R.C., Molfino, R.M. (1996) Simulation assessment of a modular assembly facility, 3rd. Intl. Conf. Concurrent Engineering and Design Automation, Cambridge, April 10-12, 37-42.

Acaccia, G.M., Callegari, M., Marzapani, R., Michelini, R.C., Molfino, R.M. (1996) Development of modular assembly facilities with store-up and by-pass 
management, 8th Europ. Simulation Symposium, ESS '96, Genova, Oct. 24-26, 289-293.

Michelini, R.C., Acaccia, G.M., Callegari, M., Molfino, R.M. (1990) Integrated management of concurrent shopfloor operations Intl. J. Computer-Integrated Manufacturing Systems (Butterworths), 1, vol. 3, 27-37.

Michelini, R.C., Acaccia, G.M., Molfino, R.M. (1994) Expert scheduler for adaptive planning of batch-varying highly-diversified products, Intl. ASMEISCIE Symp. on Flexible Automation, Kobe, July 11-18, 752-756.

Michelini, R.C., Acaccia, G.M., Callegari, M., Molfino, R.M., Razzoli, R.P. (1999) Techniques in computer integrated assembly for cost effective developments, C.T. Leondes, Ed.: Computer integrated manufacturing systems: techniques and applications, Gordon \& Breach Intl. Series in Eng., Technol. and Appl. Sci., Newark (to appear).

Tzafestas, S., Ed. (1997) Management and control of manufacturing systems, Springer Verlag Pub., London.

Womack, J.P., Jones, D.T., Roos, D. (1990) The Machine that Changed the World, Rawson Ass. NewYork.

Zaremba, M.B., Prasad, B. Eds. (1994) Modern Manufacturing: Control \& Technology, Springer Verlag, London.

\section{BIOGRAPHY NOTE}

The Authors are at Lab. di Progettazione meccanica applicata alla Robotica industriale, Dip.to di Meccanica e Costruzione delle Macchine, University of Genova, Italy, with research and teaching interest in the areas of robotics, quality engineering and industrial automation.

Dr. Rezia M. Molfino is professor of 'Controllo e regolazione dei sistemi meccanici', vicepresident of SIRI (Italian Robotics Society) and leader of many research projects in automation and robotics.

Dr. Alberto Lacchini and Dr. Giulio Maggiolo have joined the Laboratory for the work aiming at their Degree in Mechanical Engineering on factory automation.

Dr. Rinaldo C. Michelini is professor of 'Costruzione di macchine', member of the IFIP WG 5.3, ASME fellow and leader of research projects in quality engineering, diagnostics and intelligent manufacturing.

Dr. Roberto P. Razzoli is teaching 'Affidabilità e sicurezza delle costruzioni meccaniche', member of ADM, SIRI and involved in several research projects in total design, simultaneous engineering and industrial automation.

The SIFIP family of expert-simulators has been implemented, starting by 1986, as A. I. development aid, to support intelligent manufacturing applications at the design phases (to set of shopfloor lay-out) and at operation phases (to fit the scheduling policy).

The simulation environment has been exploiting several commonly used programming languages (OPS 5, G.2, MODSIM, etc.) and appropriate modules have been developed for on-line real-time operations, to be directly interfaced with the facilities and to enable onprocess adaptivity at the three execution, coordination and organisation levels.

The research activity aiming at factory automation has been developed with several 
industrial partners (COMAU, DEA, Mandelli, Speroni, etc.) and with application fields from instrumental suppliers, to pharmaceutical enterprises, from precision mechanics to textile and apparel manufacture, etc., with special interest for the on-process adaptive programming ruled by expert-governors. 